\title{
Using olfactory media cues in e-learning - perspectives from an empirical investigation
}

\author{
Anas Ali Alkasasbeh ${ }^{1,2} \cdot$ Gheorghita Ghinea $^{1}$ \\ Received: 28 February 2019 / Revised: 9 January 2020 / Accepted: 17 February 2020 / \\ Published online: 19 March 2020 \\ (C) The Author(s) 2020
}

\begin{abstract}
People interact with computers using their senses. Currently, in a digital context, traditional digital media like videos and images used to convey information to users, and these media can be used as a source of information. However, relatively few studies have been conducted on olfactory media as a source of information in a digital context. In this paper, we report on a study that examined the possibility of using olfactory media as a source of information and whether its usage as informational cues enhances learning performance and user Quality of Experience (QoE). To this end, an olfactory-enhanced quiz (web-based) was developed about four countries. The quiz contained different types of questions employing four types of digital media in their contents: text, image, audio and olfactory media. Four scents were used that were considered to be related to the respective countries. Sixty-four participants were invited to our experiment to evaluate this application. Our results revealed that usage of olfactory media synchronised with traditional digital media had a significant impact on learner performance compared to the case when no olfactory media was employed. In respect of user QoE, it was found that olfactory media influenced users positively; moreover, they were passionate about engaging with enhanced olfactory applications in the future.
\end{abstract}

Keywords Olfactory media $\cdot$ Olfactory cues $\cdot$ Traditional digital media $\cdot$ Learner performance . Quality of experience

\section{Introduction}

In the 'real', physical world, we learn through all our senses; however, in the digital world not all senses are employed in the e-learning process. Accordingly, e-learning systems have used

Gheorghita Ghinea

george.ghinea@brunel.ac.uk

1 Department of Computer Science, College of Engineering, Design and Physical Sciences, Brunel University London, London, UK

2 Computer Science Department, College of Information Technology, Mutah University, Mutah, Jordan 
traditional digital media such as images, audio and video to provide information to learners. This is aimed at enhancing their cognitive skills [2], as such media make it easier for learners to recall information needed and qualify their perception in a specific area [17]. This in turn encourages teachers to support the learning material with these types of media. Furthermore, it is possible to use these media themselves as a source of information. For example, an image of a coffee plantation could be good for learners to conjure up Brazil, as this product is widely associated with that country. That is, the image in this example is used as a cue to activate the learner's memory to recall the information needed or to aid learners to remember this information in the future, as well as making it easier to assimilate the required knowledge not to mention that a picture is worth a thousand words.

Current e-learning efforts mainly target the learner's auditory and visual modalities (and sometimes tactile too), neglecting senses such as gustation and olfaction. However, the latter has been shown to be a potent mechanism for learning since it is linked to the limbic system, which in turn is related to emotions and feelings. The challenge of bringing multisensory learning to a digital context remains, though. Nonetheless, there have been incipient efforts. As part of multiple sensory media (mulsemedia)-based learning, many researchers have explored the effects of olfactory media (scents) to help users recall information and enhance learners' performance $[1,11,12,21,36,42]$. In the experiment reported upon in this paper, we investigate whether it is possible to use olfactory media as a supplementary source of information (conveying it via the olfactory channel) alongside traditional media. Moreover, we also test whether such media could enhance learners' performance and develop their knowledge. For example, most people would travel with their emotions and imagination to countries like Brazil or Colombia when they receive a whiff of coffee.

Spatial memory saves information about places, which needs a stimulus [17] or brainstorm to recall this information. To this end, words or images can touch our memories to recall an event or place in spatial memory [24], as can smells. It is this association that we draw upon for our experimentation, as it was our assumption that olfactory media performs a vital cue for our memories, especially when it comes to recalling a piece of information about places that we have visited - or learnt about - in the past. The usage of olfactory media in such contexts is reinforced by the fact that it can help us retrieve words/phrases $[12,37]$ that may otherwise need considerable verbal or non-verbal information to obtain. For example, whilst we would need more than ten words to describe a strawberry, such as 'a red-coloured fruit shaped like a heart. Its flesh has a juicy texture......'. With olfactory media, we would potentially need only to emit a scent with the characteristic aroma of the strawberry for the fruit to be recognised. Accordingly, we decided to build an olfactory web-based application, which incorporated a quiz about four countries. The quiz contained questions that used olfactory media either as independent media or, indeed, with other traditional digital media, to examine whether such media combinations could enhance the learner's knowledge and/or serve as a source of information. In the following sections, we review the related studies in which we review the most relevant studies that employed mulsemedia in learning and other applications. After that, the experimental work is presented. In this section we explain the experimental procedure and task (whole process). Then, we discuss our results and the implications of having olfactory media on user performance and QoE. In the last section, conclusions are drawn and opportunities for future work discussed. 


\section{Related work}

Mulsemedia is the process of stimulating, joining or synchronising human senses, such as touch, olfaction and taste with the traditional ones of hearing and vision in a digital context $[15,16,33]$. Mulsemedia can be employed in a virtual environment with a range of different applications [15]. The aim of which is to enhance user Quality of Experience (QoE) [41], learner performance, human interaction and information retrieval in different tasks [1, 42].

One of the earliest applications of olfaction in a digital context is to augment applications and to enhance the interactions between people and these applications. For example, Kaye [19] developed a set of applications that used olfactory media to send information to users. In his applications, he used two types of olfactory media, namely olfactory icons and semicons. The olfactory icon is a scent related directly to the application material, such as using an orange scent with a field of fruits. The semicons (semantic icon) serves to represent a material and this case, the author designed a scent reminder. While the majority of alarms use sound a notification for an event, the scent reminder uses olfactory media that relating to it that is emitted at the time of the event or before the appointment time. Another example notification system, is that of Dobbelstein et al. [6], who developed a new wearable olfactory device (OD) used to notify users. They could change the scents using a mobile application and small cartridges, with a wearable device being used to notify the users in dangerous situations or as an emotion and memorable reminder.

Several other applications, such as entertainment applications and games, have also benefited from having olfactory media alongside traditional media. Adding olfactory media to these applications can enhance their realism and entertainment factor. In terms of increasing the sense of reality in entertainment, Suzuki et al. [39] developed an innovative application that allows people to watch olfactory-enhanced TV videos, recorded or live. The authors used closed captions and timestamps to emit the smells with scenes using an olfactory device connected to a laptop. In the VR (Virtual Reality) field, Ranasinghe et al. [31] developed a virtual cocktail (Vocktail) system that aimed at enhancing the flavour experience using multisensory stimuli. In this system, the users have the opportunity to mix a glass of cocktail by choosing the ingredients, tasting them, smelling them and observing the colours; however, ultimately they do drink only pure water.

In respect of user QoE and perception, Ghinea and Ademoye [11], examined the impact of synchronisation between related/unrelated video content and olfactory media content on user perception. Murray et al. [26] then investigated the boundaries of synchronisation between olfactory media and video content and showed that olfactory media is much more loosely coupled than traditional media. In later work, Murray et al. [28] also indicated potential ties between user QoE and certain factors such as the intensity and duration of usage. Other factors, such as user cognitive styles have also been shown to be important determinants on QoE [13, $14]$.

\subsection{Mulsemedia in e-learning}

Many studies have involved investigating the effects of using traditional digital media/ unisensory media in the learning process and on learner performance. Mayer [23] presented how people can learn more deeply from both words and images. Both words and pictures, according to this author, engage two senses (hearing and sight) to develop their knowledge. Berney and Bétrancourt [3] highlighted the positive impact of using animation on learner 
performance and knowledge acquisition. Ghergulescu and Muntean [10] reported the relationship between the gamed-based learning and learner motivation. In recent work, Bogusevschi et al. [4] and Pellas et al. [30] presented the benefits of employing AR/VR in conjunction with game-based learning on learner performance in terms of knowledge assimilation.

In the view of some researchers, the learning process, learner performance, learner motivation and learner knowledge could all be enhanced by using other new media, especially olfactory media. In this context, Tijou et al. [40] investigated the effects of using olfactory media in learning and information retrieval. They developed a virtual environment in both desktop and immersive configuration. In the desktop configuration, they showed participants the structure of organic molecules, with participants being able to rotate shapes with a mouse or by using head motions. In the immersive configuration, they asked subjects to sit in front of a large screen and examined the structure. In both cases, they used ODs to emit related olfactory media to those organic molecules to help participants remember and retrieve the associated information. Specifically, they used spearmint scent with D-Carvone organic. The authors found that participants (undergraduate students) willingly interacted with these systems. In related work, they also designed an olfaction-enhanced application for learning the letters of the alphabet. Richard et al. [32] developed a virtual environment augmented by haptic, olfactory media, auditory and visual media. They described a study whose aim was to test the effects of adding haptic and olfactory media on students' learning process, information retrieval, and mental associations. The authors used different types of scents with different energy levels as well as various visualisations. It was reported that participants were surprised at using new media in the learning process, but nonetheless were positive towards its use. To test learner performance and QoE in an information recall task, Ademoye and Ghinea [1] used six olfactory enhanced video clips in an experiment. Each video clip was $90 \mathrm{~s}$ divided into three segments, with the middle one being enhanced by olfactory media. Their results highlighted that olfactory media did not have a negative impact on information absorption.

Similar results were also found by Garcia-Ruiz et al. [7, 8], who studied the effects of using olfactory media on students' achievement. They asked 26 students to answer five questions as a pre-test about a specific topic. Then, they divided the participants into two groups. The first group received olfactory media in the form of a mint scent, while they were reading a webpage about the same topic. The pre- and post-test was extracted from the same webpage. The second group read the same web page without receiving the olfactory media. Finally, participants answered the same test. It was found that the group engaging in the olfaction-enhanced reading did slightly better in the post-test than the one which did not receive olfactory media. Furthermore, students stated that they were open to using the olfactory interface in the future. Garcia-Ruiz et al. [8] also examined the influence of using the same olfactory media (mint) on students, while they were receiving oral instructions (listening) in the English language. These instructions were used to guide the participants in navigating from one point to another in a virtual town.

Additionally, creativity in writing has been examined under the influence of olfactory media. Gonçalves et al. [18] tested several conditions including audio, scents, as well as both audio and olfactory media inside a classroom to investigate their impact on students while they were writing a short text as an experiment task. Regarding the olfactory media condition, they used hot coffee and a laurel fragrance inside the classroom. Interestingly, Kwok et al. [21] conducted a study within an actual classroom environment, equipped with olfactory devices to increase the learners' effectiveness and sensation. Specifically, in order to increase creativity and energy levels, they used a green apple scent to enhance the learner's ability to create an effective idea. Moreover, the olfactory media was synchronised with other media and events in 
their developed Smart Ambience for Affective Learning (SAMAL) system. Results showed that the experience perceived by learners, learning effectiveness and learners' engagement could be positively influenced by integrating such cognitive and affective approaches. In recent work, Zou et al. [42] reported the relationship between multisensory media, including olfactory media and recall information. They divided a network lecture into two sections in two universities. In the first section of each lecture at both universities, the lecture content was enhanced with mulsemedia, whilst the second was introduced using a traditional method (PowerPoint slides). The authors concluded that the mulsemedia gave greater enjoyment and improved the learner experience.

All of the studies mentioned above involved investigating the influence of using related or unrelated olfactory media to enhance learner performance and information retrieval. It is worth noting that the targeted information was in the material itself, e.g. video or web pages and, not in the olfactory media as such. So, to address this apparent gap, in the study we are now reporting on, the aim is to examine the olfactory media itself as the source and target of the information. Moreover, we are going to test the effects of olfactory media with other digital media or separately so as to build upon participant's prior knowledge. Finally, we aim to track the influence of using olfactory media on user QoE.

\section{Methodology}

\subsection{The task}

The purpose of the experiment was to evaluate a web-based olfactory application containing a quiz about four countries from different continents, with there being eight questions, two for each country. Each pair of questions was based on information provided to the participants using three media types: text, audio and olfactory. Table 1 provides a description of the different question types and the media used. To our knowledge, it is the first time that olfactory media itself has been used as a primary rather than secondary source of information. Participants received olfactory media for only one of the eight questions. Olfactory media was then synchronised and used in conjunction with other media (audio and text and combinations thereof, as detailed in Table 1) for three questions, whilst olfactory media was not employed at all for the other four questions.

Table 1 Study questions type and used media

\begin{tabular}{cll}
\hline $\begin{array}{l}\text { Question } \\
\text { type }\end{array}$ & Used media & Description \\
\hline T & Text only & A piece of information \\
A & Audio only & Audio file (played for $60 \mathrm{~s}$ ) \\
S & Scent only & Olfactory media (emitted for $20 \mathrm{~s}$ ) \\
F & Image & Image (Country flag) \\
AT & Audio and Text & Audio file and a piece of information \\
AS & Audio and Scent & Audio file and related scent \\
TS & Text and Scent & Olfactory media will be synchronised with a piece of textual information \\
ATS & Audio, Text and & Audio file and olfactory media will be synchronised with a piece of textual \\
& Scent & information \\
All audio files and olfactory media will be synchronised after 15 s when the web-page is completely loaded
\end{tabular}


Figures 1 and 2 show screenshots of the questions as they were displayed to participants. Clockwise, from the top left corner, Fig. 1 displays questions targeting South Africa (A- Audio information only), Brazil (TS -Textual information coupled with Scent), India ( T - Textual information only) and India (AS - Audio information coupled with Scent). Likewise, Fig. 2 displays questions targeting Japan (F- Image only), Japan (ATS - Audio and Textual information alongside Scent), South Africa (AT - Audio and Textual information), and South Africa (S - Scent only). The media components for each such question are given in Table 2. For completeness, it is mentioned that the audio used in the case of Brazil was Bossa Nova.

\subsection{Experimental material}

- Olfactory Display: In this experiment, the Exhalia Diffuser SBi4 (Fig. 3) was used to emit the scents associated with each question's content. This device can emit up to four scents at once through four independent fans and cartridges. The device was attached to a computer through a USB port in order to control the timing and selection of the fans.

- Olfactory media: Four scents were used in this experiment: curry, coffee, wilds grass and green tea. These were selected carefully to be compatible with the targeted countries, respectively India, Brazil, South Africa and Japan.

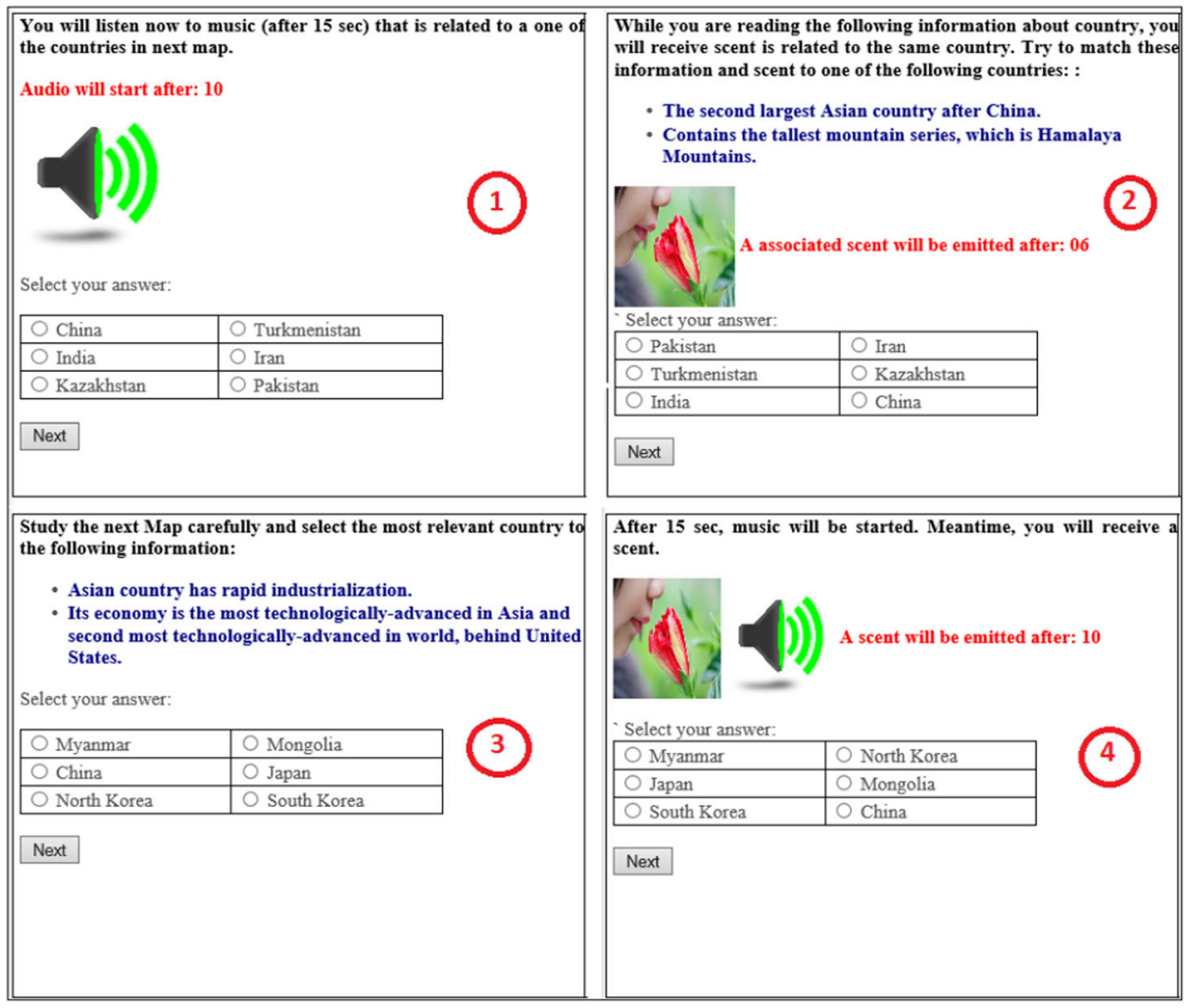

Fig. 1 A, TS, T and AS questions (clockwise from top left) 


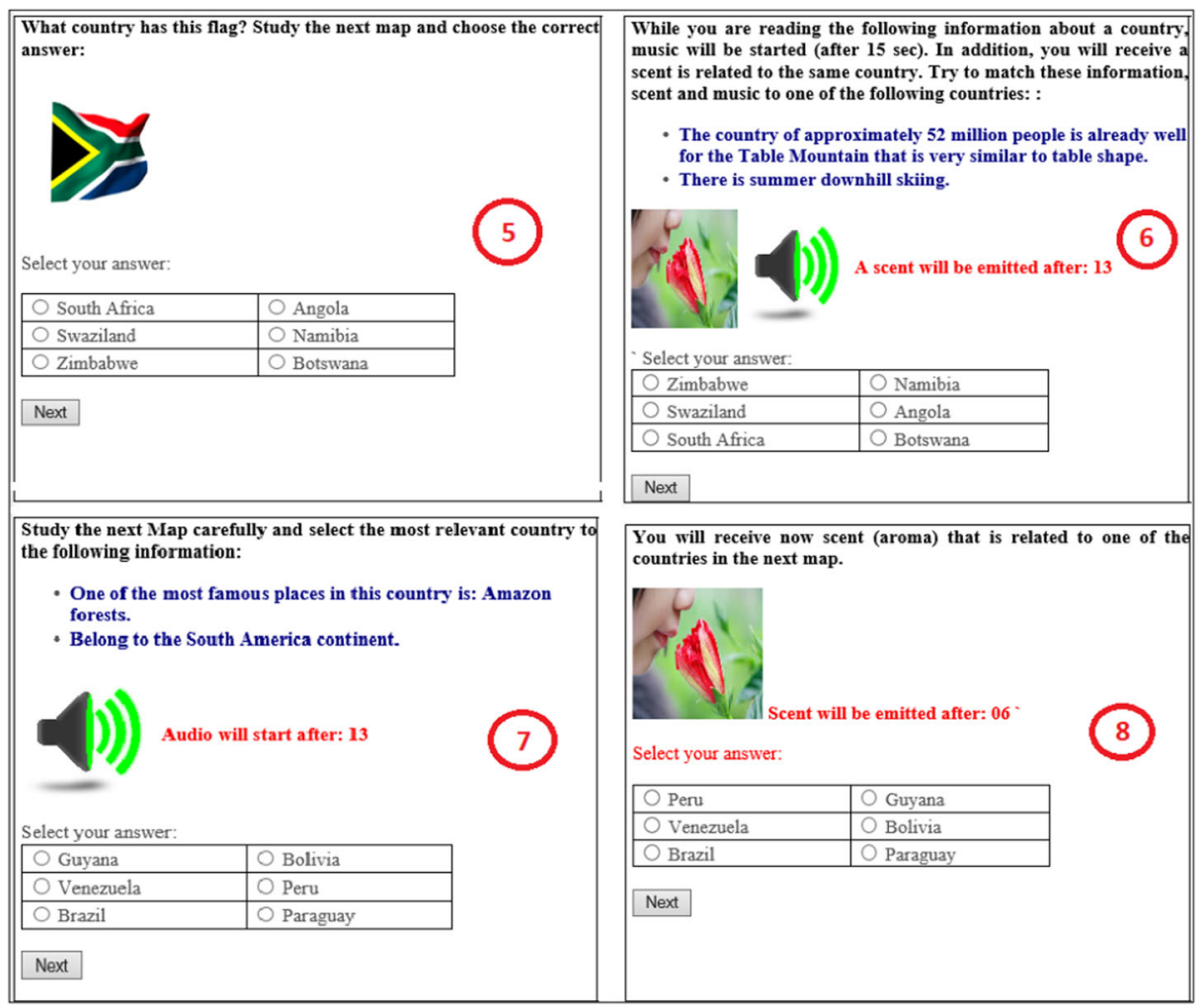

Fig. 2 F, ATS, AT and S questions (clockwise from top left)

Table 2 Media components of questions in Figs. 1 and 2

\begin{tabular}{|c|c|c|c|c|}
\hline $\begin{array}{l}\text { Targeted } \\
\text { country }\end{array}$ & Question type & Text & Scent & Audio \\
\hline $\begin{array}{l}\text { South Africa } \\
\text { (Fig. 1-part 1) }\end{array}$ & A & - & - & $\begin{array}{c}\text { Zulu a cappella } \\
\text { singing }\end{array}$ \\
\hline $\begin{array}{l}\text { Brazil } \\
\text { (Fig. 1- part 2) }\end{array}$ & TS & $\begin{array}{l}\text { - One of the most famous places in this country is: } \\
\text { The Amazon forest. } \\
\text { - Belongs to the South American continent. }\end{array}$ & Coffee & - \\
\hline $\begin{array}{l}\text { India } \\
\text { (Fig. 1-part 3) }\end{array}$ & $\mathrm{T}$ & $\begin{array}{l}\text { - The second largest Asian country after China. } \\
\text { - Contains the tallest mountain series, which is } \\
\text { Himalaya Mountains. }\end{array}$ & & \\
\hline $\begin{array}{l}\text { India } \\
\text { (Fig. 1-part 4) }\end{array}$ & AS & - & Curry & Dandiya music \\
\hline $\begin{array}{l}\text { Japan } \\
\text { (Fig. 2-part 6) }\end{array}$ & ATS & $\begin{array}{l}\text { - Asian Country has rapid industrialization. } \\
\text { - Its economy is the most technologically-advanced } \\
\text { in Asia and the second most technologically-advanced } \\
\text { in the world, behind the United States. }\end{array}$ & Green Tea & Anime Music \\
\hline $\begin{array}{l}\text { South Africa } \\
\text { (Fig. 2-part 7) }\end{array}$ & $\mathrm{AT}$ & $\begin{array}{l}\text { - The country of approximately } 52 \text { million people is } \\
\text { already well known for Table Mountain that is } \\
\text { very similar to a table shape. } \\
\text { - There's summer downhill skiing }\end{array}$ & & $\begin{array}{c}\text { Zulu a cappella } \\
\text { singing }\end{array}$ \\
\hline $\begin{array}{l}\text { South Africa } \\
\text { (Fig. 2-part 8) }\end{array}$ & $\mathrm{S}$ & - & Wild grass & \\
\hline
\end{tabular}




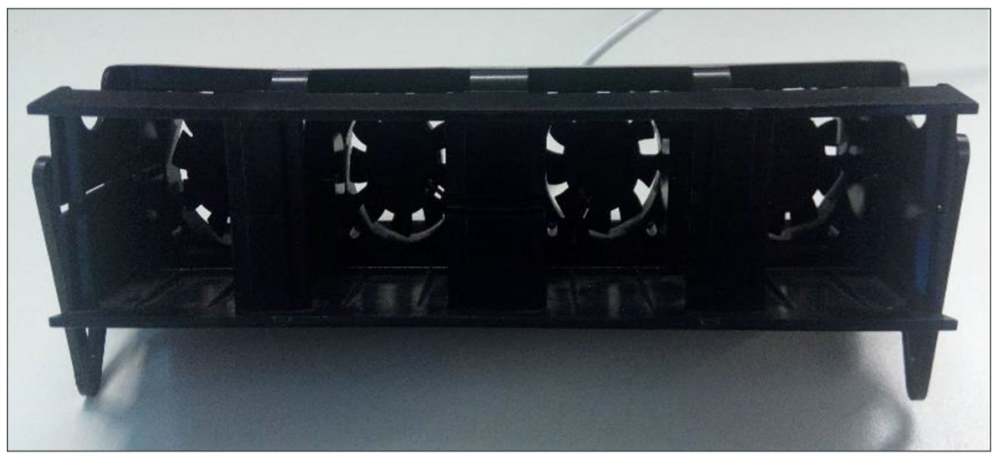

Fig. 3 Exhalia device

- Headphones: A pair of noise cancelling Sony MDR-ZX770BN headphones were used to enable participants to experience the audio component of the quiz in a similar manner.

- Olfactory-enhanced web-based application: A web-based java application was developed, JSP pages using NetBeans IDE). This application employs the olfactory device in order to emit the required scents. All the data needed in this application were retrieved from a MySQL database containing data about countries, question texts, associated scents and audio files. Furthermore, all the data, including the participants' demographic information and quiz results were stored in the same database.

- Questionnaire: A 5-point Likert scale questionnaire was employed to get feedback from the participants about the olfactory application and related scents. This questionnaire was divided into two sections: the first ten questions were used to assess the application and comprised statements drawn from the Systems Usability Questionnaire [5], while the remainder evaluated the olfactory media employed in the quiz.

\subsection{Participants}

Sixty-four participants, 36 male and 28 females, took part in the experiment (see Table 3). Their age range was between 19 and 44 years old, with a mean age of 28.65 years, and SD of 7.59 years. The majority of the participants were postgraduate students, while the rest had different educational backgrounds, including undergraduate students, from two institutions: Brunel University (UK) and Mutah University (Jordan). Moreover, some came from the countries that the experiment was based upon. Specifically, two participants were from India, three from Japan, two from Brazil and one from South Africa. The other 56 participants hailed from different other nationalities. A convenience sampling strategy was employed, whereby participants were invited to take part in the study either face-to-face, through an email, or via a phone call. Only five participants had engaged previously in an experiment that used olfactory media. Last but not least, the Brunel University Research Ethics Office had approved the study. It was made clear to users that they would not be getting any remuneration for taking part, that they could withdraw at any stage without given any reasons for doing so, and that their responses would be anonymised. 


\subsection{Experimental design}

The experimental design is detailed in Table 4. Participants were sequentially allocated to one of our groups of the study. The design was such that for a particular participant, they would be exposed to all eight combinations of media cues. Thus, each participant would be exposed to T, A, S, T, AT, AS, F and ATS question types, with two questions per each country. Similarly, for each country that the quiz targeted, there were eight question types that were used in our quiz, two questions for each group. Likewise, each particular question was accompanied by all eight media cues. For a particular participant, the order of questions was randomized, so as to avoid order effects.

\subsection{Experimental procedure}

The experiment was carried out at Brunel University London and Mutah University, Jordan. The experimental room in both universities had an open window opposite the door to get ventilation. When each participant arrived at the experimental room, s/he read the information sheet. Next, the experimental procedure was explained orally to each participant and gave him/ her a general idea about the experiment and asked if they had any questions about their participation. Finally, participants were asked whether they had any health problems preventing them from taking part in the study (e.g. cold). None reported they did and thus, after signing the consent form, they were ready to take part in the experiment.

Participants were asked to sit in front of the laptop and put the headphones on their head. The olfactory device was adjusted to be at an appropriate angle towards the participant's nose. The distance between the device and their nose was about 30-40 cm, while the angle was adjusted between $30^{\circ}$ and $45^{\circ}$ depending on the participant's characteristics, as recommended by Murray et al. [28]. Once participants were thus positioned, they were asked to click the start button of the quiz. The next page was the registration form, the completion of which allowed for the collection of demographic data about the participants including age, educational level, nationality and gender. After the registration phase, each participant received an ID number and the quiz order/ structure. The quiz had four different structures, each corresponding to a particular experimental condition, and participants were in equal measure assigned to one of the groups. To ensure there was an equal number of participants for each group (quiz

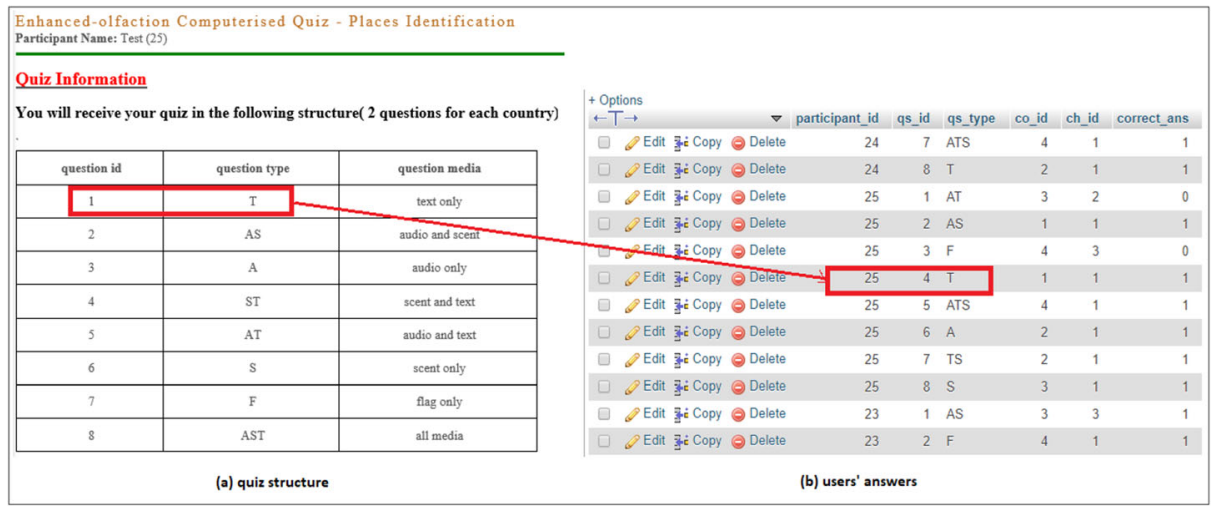

Fig. 4 Example of the quiz's structure 
Table 3 Participants' distribution

\begin{tabular}{lll}
\hline & Brunel University London & Mutah University Jordan \\
\hline Male & 33 & 3 \\
Female & 25 & 3 \\
\hline
\end{tabular}

structure), participants were assigned sequentially rather than randomly and this guaranteed that all question types would be tested equally for each country. Table 4 shows the different structures designed for this experiment. For example, Fig. 4 (a) shows the quiz's structure for the 25th participant of our empirical study. In this example, the participant was allocated to Group1. As mentioned in section 3.4, the order of questions was randomized during the quiz. For example, in this particular case, the 25 th participant received a ' $\mathrm{T}$ ' type (textual only) question about 'India' in the 4th question, as depicted in Fig. 4 (b).

Once the quiz had ended, as aforementioned, each participant was asked to fill in a questionnaire (see Table 5) about the enhanced-olfactory application (Item 1-Item 10), and the use of olfactory media and its impact on the user experience in our application (Item 11 Item 20). The duration of our experiment, according to the experimental log collected, was between 25 and $30 \mathrm{~min}$.

\section{Results and discussion}

\subsection{The impact of olfactory media on user performance}

The results of the quiz in our experiment show that the olfactory media acted as a primary source of information, especially when used together with other types of digital media. In order to establish this, a t-test was conducted with a significance value of $p<0.05$. The results show a significant improvement with respect to participants' performance, especially in respect of the difference between those questions that employed olfactory media in conjunction with other types of digital media such as, ST (Text and Scent), ATS (Audio, Text, and Scent) or AS (Audio and Scent).

Figure 5 shows the average of scores achieved by all participants for each question and highlights that questions that were augmented with olfactory media (ST, AS, ATS and S) had higher than average scores in comparison with those that did not. However, for those questions that had only olfactory media (S) as their content, the results (average scores) revealed no significant differences compared to those that had only traditional digital media for content such as Text-only " $T$ " and Audio-only "A" questions. For example, the average score in the "A" questions was $46 \%$, while for the "S" questions this was $42 \%$. In contrast, the average score with the "AS" (audio and olfactory media) was 73\%, which is a significant improvement if this is compared with the average score in "A" questions, which was $46 \%$.

As can be seen in Fig. 5, the average score of the "S" questions had no significant difference compared with "AT", "T" or "A" questions, the average score of "S" questions was approximately the same as the average score of "AT", "T" or "A" questions or slightly higher. Hence, a scent can serve as a primary source of information in a digital learning context, if it is selected carefully to be compatible and related to the targeted information. For this reason, the compatibility between the scent and the information needed should be 
Table 4 Experimental design

\begin{tabular}{lllllllll}
\hline Question & 1 & 2 & 3 & 4 & 5 & 6 & 7 & 8 \\
\hline Group 1 & T & AS & A & TS & AT & S & F & ATS \\
Group 2 & A & TS & AT & S & F & ATS & T & AS \\
Group 3 & AT & S & F & ATS & T & AS & A & TS \\
Group 4 & F & ATS & T & AS & A & TS & AT & S \\
Group 5 & AS & T & TS & A & S & AT & ATS & F \\
Group 6 & TS & A & S & AT & ATS & F & AS & T \\
Group 7 & S & AT & ATS & F & AS & T & TS & A \\
Group 8 & ATS & F & AS & T & TS & A & S & AT \\
Target country & India & India & Brazil & Brazil & South Africa & South Africa & Japan & Japan \\
\hline
\end{tabular}

considered in the question content to convey the information needed easily. For example, in the case of Brazil, the coffee scent was selected, as it is associated with the most popular agricultural product in that country. As far as India is concerned, the curry scent was chosen which resonates with Indian cuisine.

From Fig. 5, it can be observed that user average quiz scores were higher when olfactory media was used in conjunction with other traditional media. To confirm whether these differences are statistically significant, the paired samples t-test was used to compare the results of questions that had traditional media(x) in their content with those that had the same traditional media(x) but were synchronized with olfactory media. Table 6 shows the results of this comparison, where a significant difference in all types of questions enhanced by olfactory media can be seen. We thus conclude that olfactory media improves the learner's performance, especially when used in conjunction with other traditional media such text and scent (ST). Whilst the benefits of using olfaction in a digital learning setting have also been tested by Kwok et al. [21] and Zou et al. [42], to the best of our knowledge this is the first time when a) olfactory media is used as an actual informational source, and b) it is shown that learner scores are actually higher

Table 5 The questionnaire's items

Q Developed application (system usability)

1 I found the application easy to use

2 I did not enjoy using the application.

3 I felt very confident using the application.

4 I needed to learn a lot of things before I could use this application

5 I found the various components in this application were well integrated.

6 I thought there was too much inconsistency in this application.

7 I think that most people would like to use this application.

8 I think that I would need the support of a technical person to be able to use this application.

9 I think that I would like to use this application frequently.

10 I found this application very cumbersome to use.
Q Used scents (effects)

11 The scent was emitted at the appropriate time.

12 The scents were distracting

13 The olfactory device emitted the scents for an appropriate duration.

14 The scents lingered for too long after they were emitted.

15 The scents helped me answer the questions.

16 The scents were annoying.

17 I would like to use scents in the computerised test in the future.

18 I found the intensity of the smell too strong.

19 I found the smells helped me concentrate on my task.

20 I did not find the emitted scents were related to the quiz. 
Table 6 T-test comparing quiz scores (country) when using traditional media and olfaction-enhanced media

\begin{tabular}{|c|c|c|c|c|c|c|c|c|c|c|c|c|}
\hline \multirow[t]{2}{*}{ Type } & \multicolumn{3}{|l|}{ India } & \multicolumn{3}{|l|}{ Brazil } & \multicolumn{3}{|c|}{ South Africa } & \multicolumn{3}{|l|}{ Japan } \\
\hline & $\mathrm{t}$ & $\mathrm{df}$ & Sig & $\mathrm{t}$ & $\mathrm{df}$ & Sig & $\mathrm{t}$ & $\mathrm{df}$ & Sig & $\mathrm{t}$ & $\mathrm{df}$ & Sig \\
\hline $\mathrm{T}-\mathrm{TS}$ & -2.782 & 15 & 0.014 & -2.406 & 15 & 0.029 & -3.873 & 15 & 0.002 & -4.038 & 15 & 0.001 \\
\hline$A-A S$ & -2.423 & 15 & 0.029 & -2.782 & 15 & 0.014 & -2.406 & 15 & 0.029 & -2.406 & 15 & 0.029 \\
\hline AT - ATS & -2.392 & 15 & 0.01 & -2.782 & 15 & 0.014 & -2.782 & 15 & 0.014 & -2.739 & 15 & 0.015 \\
\hline
\end{tabular}

when olfactory media is used in conjunction with other media, as opposed to just employing olfactory media by itself.

A one-way ANOVA test was also conducted to confirm whether there is a statistically significant difference between (T, TS), (A, AS) and (AT, ATS) questions for all the results as a whole. The analysis of variance showed that the effect of having the olfactory media with other traditional media was significant, $(\mathrm{T}, \mathrm{TS}): \mathrm{F}(1,126)=42.894, p<0.05 ;(\mathrm{A}, \mathrm{AS}): \mathrm{F}(1,126)=$ $27.684, p<0.05$; (AT, ATS): F $(1,126)=42.546, \mathrm{p}<0.05$.

\subsection{The impact of olfactory media on user QoE}

The QoE questionnaire had three groups of items respectively aimed at assessing the olfactoryenhanced application's usability, olfactory media and future prospects for using olfactory-enhanced applications. To check the reliability of the responses, the Cronbach's Alpha coefficient was calculated, which was found to be $\alpha=0.7136$ and thus revealed good reliability [9]. The overall response to this questionnaire was positive (Fig. 6), with the average of all responses being 3.64 (where responses to the negatively-phrased items of our questionnaire were appropriately mirrored). The one-sample test was used to analyses these responses, with the results indicating that responses for all the questionnaire items are statistically significant $(\mathrm{df}=63, \mathrm{p}<0.05)$.

\subsubsection{System usability scale (SUS)}

The first ten questions of our user QoE questionnaire (Table 5) incorporated the system usability (SUS) scale. This measures the satisfaction levels of users through such indicators as accessibility, usability and effectiveness. The SUS calculations [34, 35]; were conducted to process the participants' responses for the SUS items in our questionnaire. These calculations were performed for each participant in our experiment. The results show (Fig. 7), that the average SUS score from all 64 participants in our study is 70.11, which is higher than the SUS mean value of 68 [34].

Table 7 The relationship between concentration/helpful responses and the average score in the olfactionenhanced questions

\begin{tabular}{llllll}
\hline Questionnaire items & $\begin{array}{l}\text { Agreed/ } \\
\text { S. Agreed }\end{array}$ & AS & ST & Scent-only & AST \\
\hline Scents were Helpful & $36 / 64$ & $30 / 36$ & $28 / 36$ & $16 / 36$ & $31 / 36$ \\
& $(56 \%)$ & $(85 \%)$ & $(78 \%)$ & $(45 \%)^{*}$ & $(86 \%)$ \\
Concentration & $37 / 64$ & $29 / 37$ & $28 / 37$ & $17 / 37$ & $29 / 37$ \\
& $(57 \%)$ & $(79 \%)$ & $(77 \%)$ & $(46 \%)^{*}$ & $(79 \%)$ \\
\hline
\end{tabular}

*The average of scores in the scent-only questions was $42 \%$ 


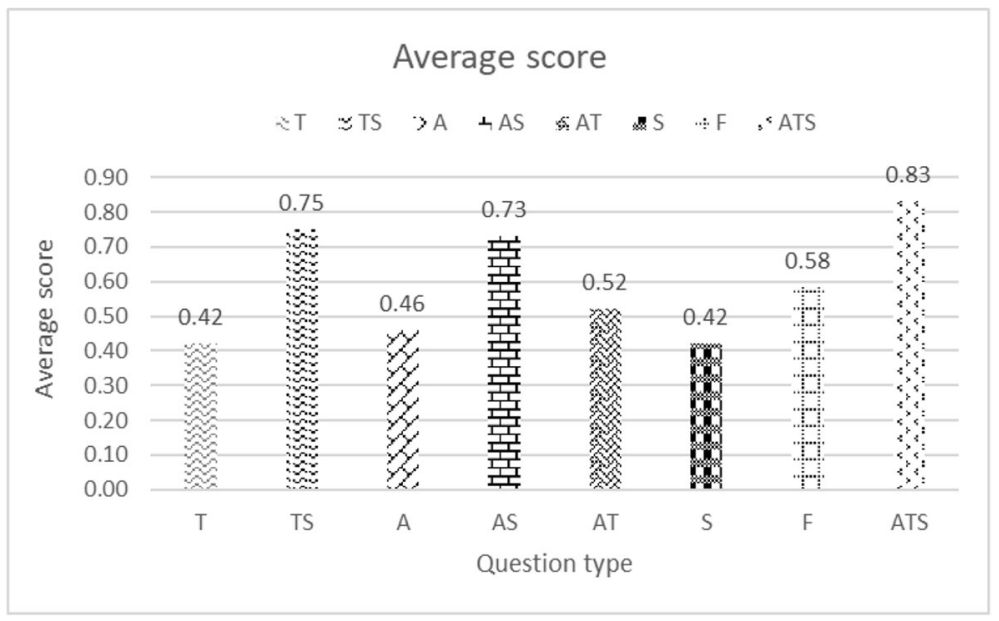

Fig. 5 Average scores per each question type

In order to interpret these scores, the SUS score was normalized and converted it to a percentile rank, as shown in Fig. 7 (a), and then generated the letter grades from A to F. As can be seen in Fig. 7 (b), the percentile rank of the average SUS score (68) is 50\% (C). According to Sauro [34, 35], our SUS scores were ranked as following: A (>80.3, Excellent), B (68-80.3, Good), C ( $=68,50 \%$, Accepted), D (51-68, Poor) and F ( $<50$, Awful). In the following bulleted items, the participants' responses for the SUS items are discussed for each item in turn:

- Item 1 - I found the application easy to use: Of the 64 participants who responded to this question, $83.5 \%$ agreed that the application was easy to use and only $4 \%$ were neutral. No issues were encountered in respect of ease of use (see Fig. 8, Item 1).

- Item 2 - I did not enjoy using the application: As shown in Fig. 8 (Item 2), a high proportion of the participants, $69 \%$, enjoyed using the olfactory-enhanced application whereas $8 \%$ did not enjoy it, and $23 \%$ reported being neutral regarding this.

- Item 3 - I felt very confident using the application: In response to this question, $81 \%$ of the participants responded that they were confident, $13 \%$ were neutral, and hence, none indicated that they were unconfident (see Fig. 8, Item 3).

- Item 4 - I needed to learn a lot of things before I could use this application: As discussed above, the application was easy to use and thus, the users did not need to learn much about it. Of the study population, $60 \%$ said they did not need to learn how to use this

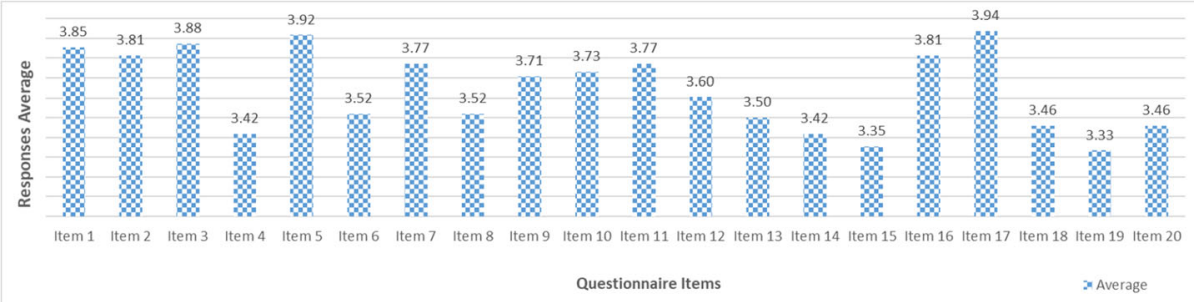

Fig. 6 Response average for QoE questionnaire items in our study 


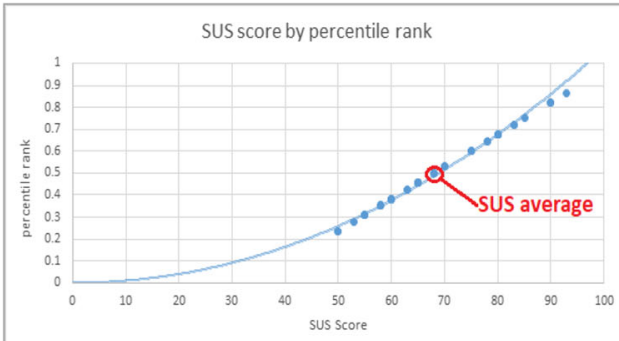

(a)

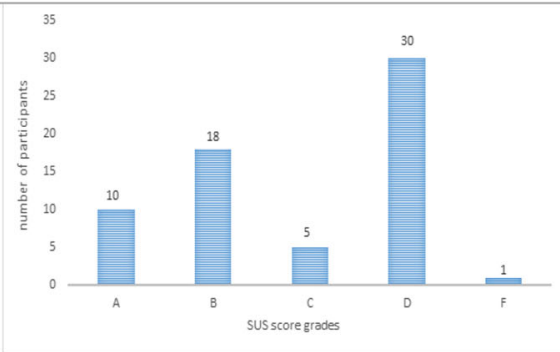

(b)

Fig. 7 SUS score percentile rank and grades

application, whilst $19 \%$ were neutral on this matter. In contrast, $21 \%$ of the participants suggested that they might have needed training in advance to use the application, which would be expected in the case of any newly developed application (see Fig. 8, Item 4).

- Item 5 - I found the various components in this application were well integrated: The main component of our application is comprised of web pages that include texts, images,

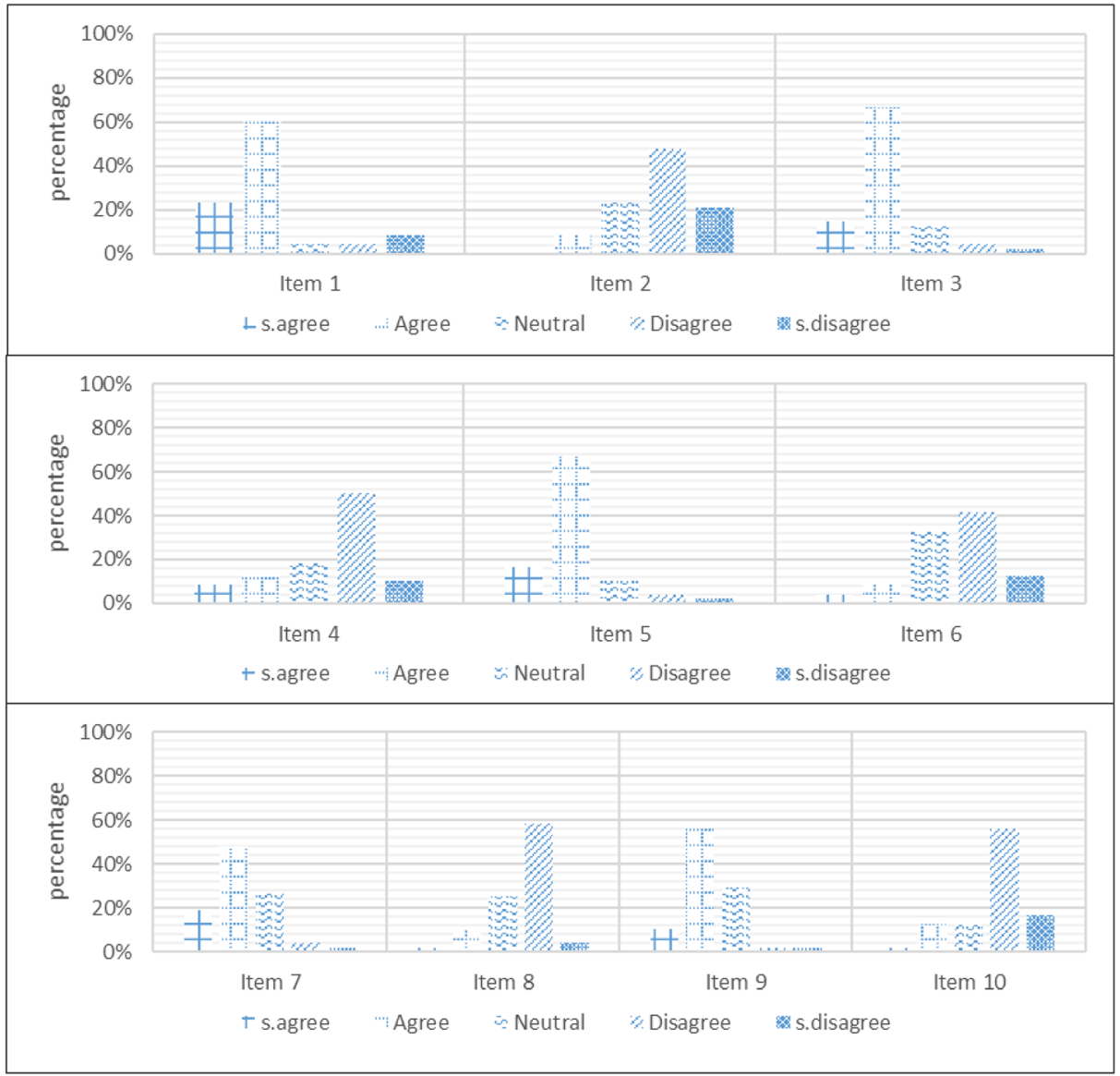

Fig. 8 SUS items responses 
audio and olfactory media. These components were arranged together depending on the question type and they could be rearranged by teachers depending on the content and according to the student's abilities. $83 \%$ of participants found the application's components to be well integrated, with $10 \%$ being neutral regarding this (see Fig. 8, Item 5).

- Item 6 - I thought there was too much inconsistency in this application: As shown in Fig. 8 (Item 6), all quiz components were arranged according to the question type and its contents. 54\% participants found the applications components to be coordinated. $34 \%$ were neutral about this, and $12 \%$ disagreed.

- Item 7 - I think that most people would like to use this application: more than two third of the participants reported that people would like to use this type of application and only $6 \%$ disagreed. $27 \%$ of participants were neutral on this matter (see Fig. 8, Item 7).

- Item 8 - I think that I would need the support of a technical person to be able to use this application: The developed application is a web-based connected to the olfactory device (Exhalia Diffuser SBi4) to emit the required scents when needed. We decided that the application should be plug and play. That is, the users could run the application, plug in the device and replace the scent cartridges. Hence, they did not need help from a technical person for in each run. Almost $63 \%$ of the participants responded that the application did not need technical assistance; a minority of $12 \%$ claimed that it did, whilst $25 \%$ of participants were neutral on this issue (see Fig. 8, Item 8).

- Item 9 - I think that I would like to use this application frequently: As reported by participants, $67 \%$ of them would like to use the olfactory-enhanced applications in their daily life, with $29 \%$ being neutral regarding this (see Fig. 8, Item 9).

- Item 10 - I found this application very cumbersome to use: All the components and steps in our application were well integrated. Accordingly, $73 \%$ of our participants found the navigation and procedure were easy and expeditious, $14 \%$ were neutral regarding this, whilst $13 \%$ agreed that the application was cumbersome to use (see Fig. 8, Item 10).

\subsubsection{The impact of olfactory media properties on user QoE}

As olfactory media is the primary player and target in this study, a number of items in the questionnaire were incorporated to measure the impact of its properties on participants' experience and performance, these being: starting time, duration, lingering and intensity. More

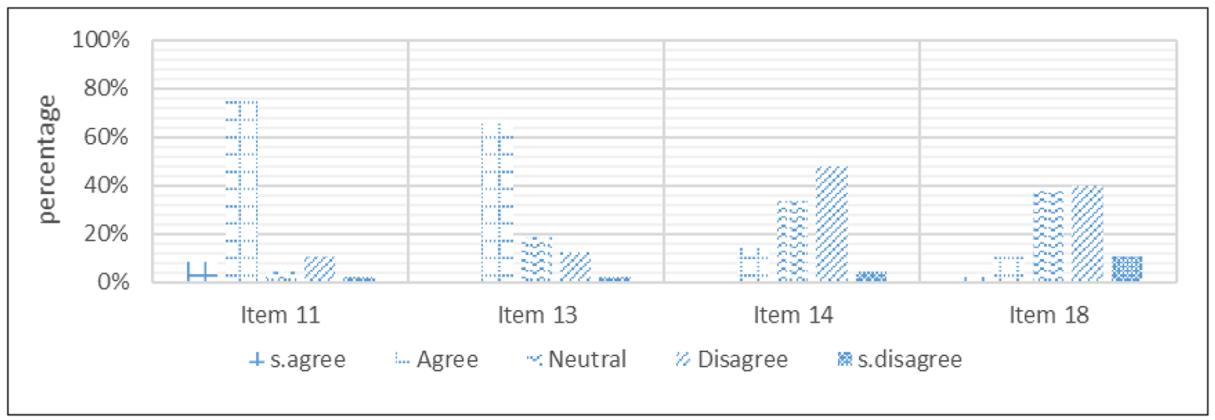

Fig. 9 Olfactory media Characteristics' items 
details about these properties and the participants' responses are provided in the following subsections (see Fig. 9).

- Item 11 - The scent was emitted at the appropriate time: In our study, we used a webbased application and we set up the starting time to be after $15 \mathrm{~s}$ in order to be sure that the web page had been loaded completely. The question asked was "The scent was emitted at the appropriate time", to which $83 \%$ of participants responded that the olfactory media was started at the appropriate time. Only $12.5 \%$ of participants perceived that the olfactory media was not sent in time. It should be noted that a timer was used to alert the participants when the olfactory media was going to be emitted, as shown in Figs. 1 and 2. It is to be noted that the guidelines were followed of Murray et al. [28] who found that users preferred to receive the olfactory media when synchronised with a video or after the video sequence.

- Item 13 - The olfactory device emitted the scents for an appropriate duration: This pertains to how long the used scent was emitted for. Participants were asked whether "The olfactory device emitted the scents for an appropriate duration". $67 \%$ of them found the duration to be appropriate, $19 \%$ were neutral and $14 \%$ responded that the duration was not enough to recognise the scent received. In fact, the olfactory media was emitted for $20 \mathrm{~s}$ to enable participants to recognise the emitted scent and thus, respond to the targeted question. Like the audio segment duration, the olfactory media duration is a crucial factor, because, as has been reported in the literature, the human olfactory system is shown to react directly to the received scents. It has been recommended that "the total perception time for the scent to be fixed at $2.5 \mathrm{sec"} \mathrm{[20],} \mathrm{which} \mathrm{is} \mathrm{unlike} \mathrm{vision} \mathrm{or} \mathrm{hearing.} \mathrm{Hence,}$ people need enough time (not less than $2 \mathrm{~s}$ ) to react to the emitted olfactory media [11].

- Item 14 - The scents lingered for too long after they were emitted: This refers to the continued presence of scent in the surrounding air after the specified duration, which was $20 \mathrm{~s}$ for each question (in our case). Actually, scent lingering has a strong relationship with scent intensity; the greater the intensity the longer its lingering after emission. $15 \%$ of those who answered this question reported that the scent lingered for too long, whilst $33 \%$ were neutral on this matter. However, 52\% of participants disagreed that the scent lingered for too long. This is particularly important, as the issue of scent lingering has been shown to be a significant challenge in a olfactory-related media studies [29, 38], yet was not found to be a negative issue in our empirical investigation.

- Item 18 - I found the intensity of the smell too strong: Like audio quality or image resolution, scent intensity could affect the user experience. A too low scent intensity may lead to the user not recognising it, whilst a too high intensity could be considered distracting or annoying. In this context, Leenders et al. [22] investigated the scent intensity and recommended that "The intensity level has to be carefully calibrated in order to get measurable effects on evaluations and behaviour". Also, they reported that a high level of scent intensity might result in confusion between pleasant and unpleasant scents. In our experiment, we considered the intensity issue by adjusting it using the Exhalia device and our application. In this respect, $12.5 \%$ of the participants were indifferent to the intensity, while 50\% disagreed with the statement that the intensity was strong, and $37.5 \%$ were neutral. These responses highlight that scent intensity was not perceived to be an issue by quiz participants. 
Overall, with respect to the scent emission duration and intensity, our assumptions about the impact of scent intensity and duration on users' QoE and performance concurred with what was indicated by Murray et al. [27]. They hypothesized that user QoE could be affected by scent intensity and duration. Also, in terms of starting time and emission duration, Murray et al. [26] investigated the boundaries of synchronization between the olfactory media and the video content. They found users need between $2.7 \mathrm{~s}-3.7 \mathrm{~s}$ to recognize the emitted scent which requires an appropriate adjustment in the starting time of the device's fans. For this reason, they examined different skews from -30 s to 30 s. For example, they found " $+5 \mathrm{~s}$ is much closer to be the correct time than $-5 \mathrm{~s}$ ". In our work, the olfactory data was synchronized (scent) after $15 \mathrm{~s}$ (the mid-point), while the user was already engaged in reading text or listing to music, in line with earlier reported good practice by [11]. For example, in the text-scent (TS) condition, users viewed a webpage containing information (text $\mathrm{T}$ ) about a country. After $15 \mathrm{~s}$, while the users were reading the text, they then experienced related olfactory data that lasted for $20 \mathrm{~s}$. Also, as shown in Fig. 10, the $25 \mathrm{~s}$ timespan after emitting the required scent (35- 60s) was used to dissipate the scent (and reduce the effects of scent lingering), and was spent by users to read the question text or indeed to answer the question itself.

In the above subsection the four factors that affect olfactory media and its impact on users were reviewed. We believe the presence of olfactory media has a positive impact on learner experience and performance. To investigate this, our questionnaire involved some items that related to the emitted olfactory media, which shall be analyzed next:

- Item 15 - The scents helped me answer the questions, and Item 19 - I found the smells helped me concentrate on my task: According to the literature [25], the concentration level has a positive or negative effects on users during a task. For this reason, quiz participants were asked whether the olfactory media helped them to concentrate during the task. According to their responses, 56\% of them agreed or strongly agreed that the scents help them to do so, as shown in Fig. 11. These results concur with [25] who elicited that olfaction has a positive impact on users whilst undertaking tasks. In terms of help, the proportion of people who agreed or strongly agreed with the statement "The scents helped me answer the questions." was 57\%, which again showed a strong user support for the use of olfaction in e-learning.

As we had a relatively high percentage of people claiming that the olfactory media heightened their concentration and helped them to answer the quiz's questions. To further investigate these claims, user scores were tested for all questions that incorporated olfactory media. In this respect, it was found that $56 \%$ of users agreed that the scents were helpful, and that $57 \%$ agreed that the scents helped them concentrate (Table 7). Of these, we see that, remarkably, $80 \%$ of users answered questions which employed combinations of olfactory media with other traditional media (i.e. AS, ST, AST) correctly, yet this proportion experiences a drastic drop to around $45 \%$ when only olfactory media is employed. This seems to suggest that olfactory media has to be used in conjunction with other media in order to obtain good learner achievement, and not by itself.

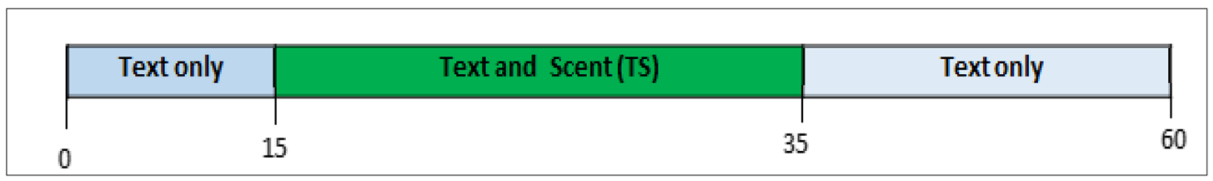

Fig. 10 Synchronisation between text and scent in TS questions 


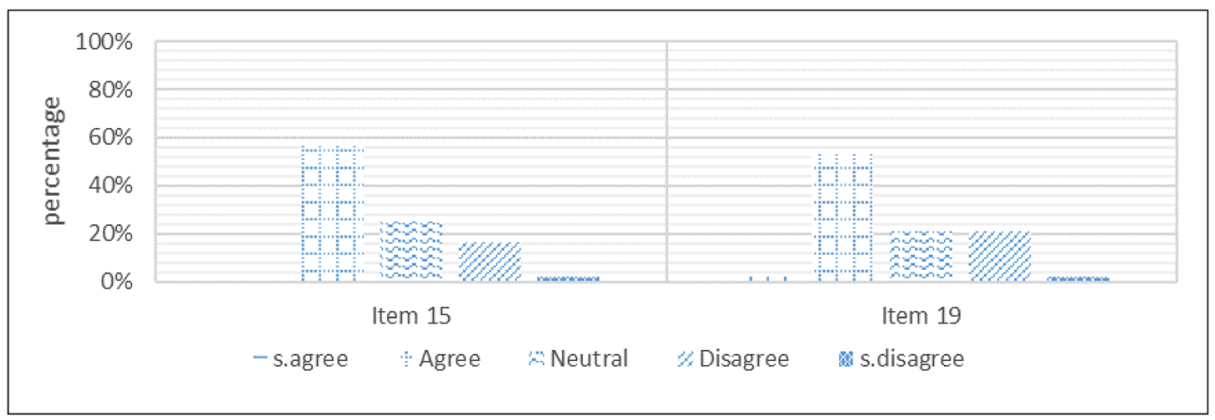

Fig. 11 Concentration and help

- Item 16 - The scents were annoying: Sometimes, users do not like to use more than one form of media when engaging with an application, such as a learning package. In our case, three types of media were used, namely text, audio and olfactory media, individually or synchronised with each other. In addition, the type of olfactory media sometimes affects the user QoE, as found by Murray et al. [28]. Hence, participants were asked whether the presence of olfactory media annoyed them when they were answering the questions. As shown in Fig. 12, only $12.5 \%$ of participants reported that the olfactory media annoyed them when answering the questions, while $77 \%$ reported they were not annoyed, with $10.5 \%$ being neutral. These results are similar to those obtained by [42] who found that multisensorial effects were not perceived as disturbing when employed in an e-learning context. Nonetheless, this is also probably due to the fact that the smells incorporated in our study had a positive hedonic valence (i.e. pleasant), as previous research [1] has revealed that unpleasant scents (with negative hedonic valence) can be perceived as annoying.

- Item 12 - The scents were distracting: Scents were used as a source of information in the study reported here. Nonetheless, participants might have perceived the emitted scents as distracting. This was not the case however, for, as shown in Figs. 12, 69\% of participants responded that the olfactory media did not cause them any distraction, with the remainder of participants being neutral. As mentioned above, the olfactory media that was used in our study was pleasant and related to what presented in the question. For this reason, the olfactory media was

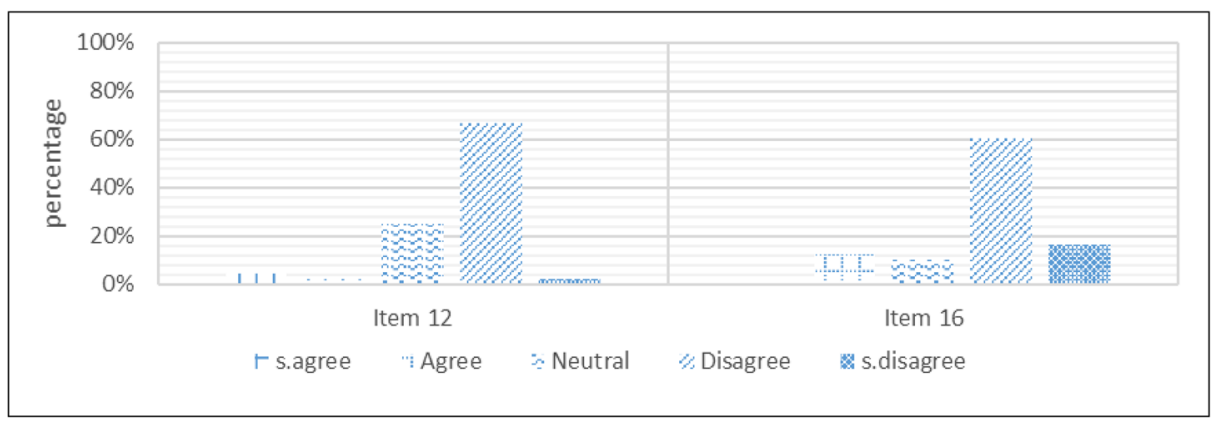

Fig. 12 Annoyance and distraction of olfactory effects 
not perceived as being distracting and is generally in line with what has erstwhile been reported in the literature [11].

- Item 20 - I did not find the emitted scents were related to the quiz: As pointed out, in some questions the olfactory media was used itself as a source of information in terms of the quiz content. The issue of association/relavance of the olfactory media had been investigated by Ademoye and Ghinea [1], who showed that in order to enhance the perceived sense of realism, olfactory media needed to be semantically congruent with the audio-visual content. For this reason, it was important for users to recognize the emitted scent and this had to be associated with the information needed. Accordingly, our participants were asked about this issue. $52 \%$ of them indicated that the emitted scent was related, with $29.2 \%$ having neutral feelings. Only $18.8 \%$ of participants reported that the olfactory media was not associated with the information needed (see Fig. 13).

\subsubsection{The impact of olfactory media on users' future trends}

- Item 17 - I would like to use scents in the computerised test in the future: Participants were also asked about their intention to engage with olfactory-enhanced applications for learning purposes in the future. We found, as shown in Fig. 14, that the percentage of users willing to use this application frequently in the future was an overwhelming $79 \%$. In contrast, $8 \%$ did not want to do so, whereas $13 \%$ were indifferent on this matter. These findings concur with those of [7, 8, 42], who found that students were open to the use of mulsemedia (included olfactory media) interfaces in the future. Finally, it is worth mentioning that some participants showed their enthusiasm were very enthusiastic regarding the experiment and the olfactoryenhanced application. Remarks such as "I really like this experiment" and "Your application was great" were noted. These responses are considered a positive indicator towards the deployment of such olfactory-enhanced mulsemedia e-learning applications in the future.

\section{Conclusion}

The study reported in this paper examined the impact of using olfactory media as a source of information in a digital quiz on learners' performance and QoE. To this end, an olfactory-

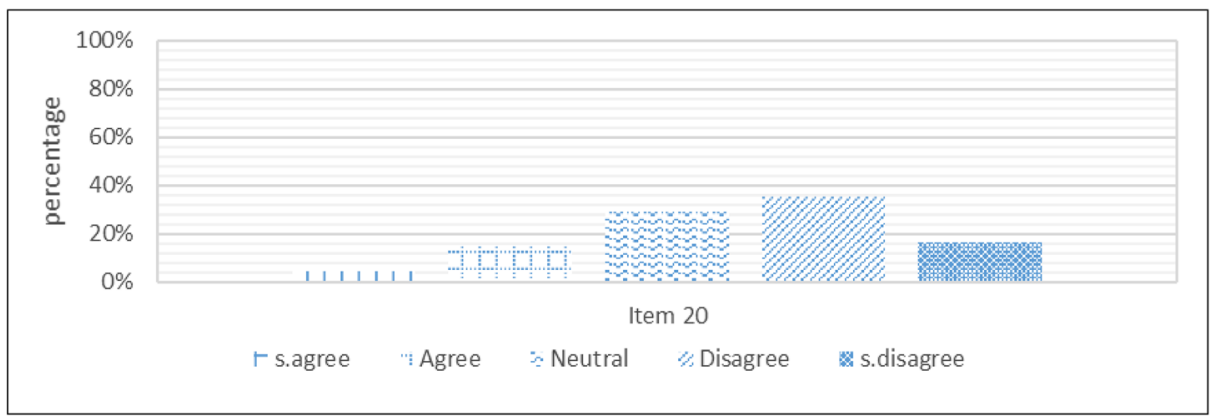

Fig. 13 Scent association 


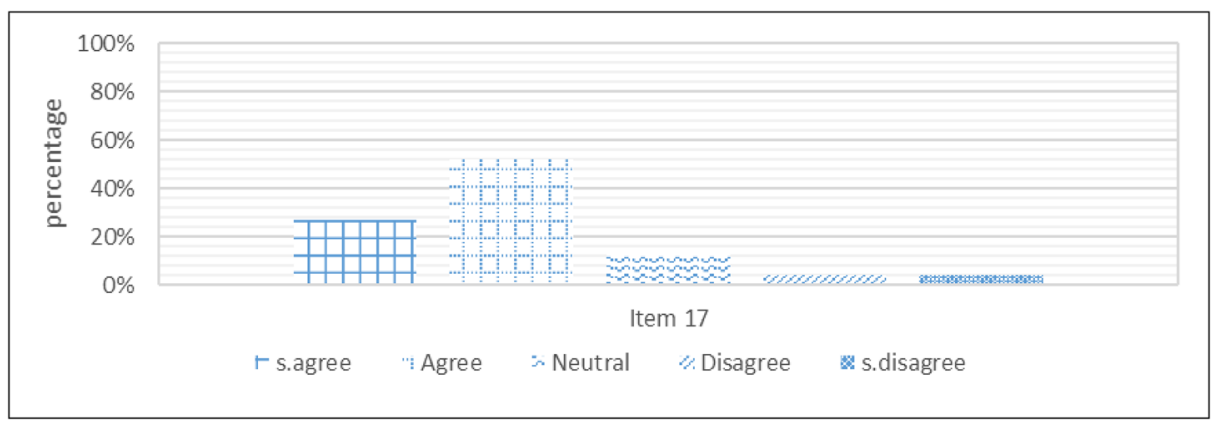

Fig. 14 Future user trends

enhanced application was developed that contained a quiz about four countries of the world. Half of the questions in this quiz were augmented by olfactory media (possibly in combination with other types of media), whilst the other half were not.

The results revealed a significant difference between the unenhanced olfactory questions and the enhanced ones. However, in regard to the scent-only questions, it was found no significant difference between this type and traditional media like text-only or audio-text questions. Nevertheless, the average score of the olfactory-enhanced questions were found to be acceptable when compared with the traditional media ones. It is noteworthy that, in respect of the quiz results, we found that olfactory media enhanced the learners' performance, and helped them to get the information needed, especially if it is used in combination with other media, e.g. text with scent, audio with scent, or text/audio with scent.

As far as user QoE is concerned, our study confirmed that the presence of olfactory media in an e-learning setting enhances the level of enjoyment and confidence of users. Also, it was found that the olfactory media characteristics like duration, lingering and intensity did not negatively affect the user performance and that the majority (two thirds) of our participants stated that the emitted scents were helpful and helped them concentrate to achieve good learning results, especially when olfactory media was used in combination with other traditional media. Lastly, it is to be remarked that many of the participants were enthusiastic about further using olfactory-enhanced applications It is thus our intention to develop new applications that use olfactory media as a major component and key-information provider and to further explore how best to integrate this media for digital learning.

Some issues should be considered when it comes to employing olfactory media in a digital context. Firstly, not all learning content is suitable for having olfactory cues because of the lack of congruency between learning content and relevant olfactory media. In this case, semantically unrelated/incongruent olfactory media enabling information recall (e.g. lavender) could be used with the content as an indicator or a stimulator; however, more work is needed to better understand how to use and integrate such semantically incongruent olfactory media in elearning. Another issue is that most of the work done in this area has dealt with able-bodied participants. However, the use of olfaction as a sensory substitution, or potential crossmodal interactions facilitated by the olfactory channel, have to be studied further in a digital context. In so doing, we will gain deeper insights into how olfaction can be used to make the digital world more accessible to individuals with, e.g. limited vision or hearing.

Finally, we acknowledge some limitations of our work. Firstly, our SUS and QoE evaluation have a lack of multiple items for a given construct. Future work should be undertaken 
with more items for each construct so as to enhance consistency and validity. Lastly, of the traditional media employed in our developed application, there was one notable absence video. Future work will also involve video coupled with olfactory media as a media to convey learner information.

Open Access This article is licensed under a Creative Commons Attribution 4.0 International License, which permits use, sharing, adaptation, distribution and reproduction in any medium or format, as long as you give appropriate credit to the original author(s) and the source, provide a link to the Creative Commons licence, and indicate if changes were made. The images or other third party material in this article are included in the article's Creative Commons licence, unless indicated otherwise in a credit line to the material. If material is not included in the article's Creative Commons licence and your intended use is not permitted by statutory regulation or exceeds the permitted use, you will need to obtain permission directly from the copyright holder. To view a copy of this licence, visit http://creativecommons.org/licenses/by/4.0/.

\section{References}

1. Ademoye OA, Ghinea G (2013) Information recall task impact in olfaction-enhanced multimedia. Applications ACM Trans Multimed Comput Commun Appl (TOMM) 9(3):17

2. Astleitner H, Wiesner C (2004) An integrated model of multimedia learning and motivation. Journal of Educational multimedia and Hypermedia 13(1):3-21

3. Berney S, Bétrancourt M (2016) Does animation enhance learning? A meta-analysis. Comput Educ 101: $150-167$

4. Bogusevschi D, Bratu M, Ghergulescu I, Muntean CH, Muntean GM (2018, April) Primary school STEM education: using 3D computer-based virtual reality and experimental laboratory simulation in a physics case study. In Ireland International Conference on Education. IPeTEL workshop, Dublin

5. Brooke J (1996) SUS-A quick and dirty usability scale. Usability evaluation in industry 189(194):4-7

6. Dobbelstein D, Herrdum S, Rukzio E (2017, September) inScent: a wearable olfactory display as an amplification for mobile notifications. In Proceedings of the 2017 ACM International Symposium on Wearable Computers (pp 130-137). ACM

7. Garcia-Ruiz M, El-Seoud SA, Edwards A, Aljaam JM, Aquino-Santos R (2008a) Integrating the sense of smell in an educational human-computer interface. Interactive Computer Aided Learning

8. Garcia-Ruiz MA, Edwards A, Aquino-Santos R, Alvarez-Cardenas O, Mayoral-Baldivia MG (2008b, November) Integrating the sense of smell in virtual reality for second language learning. In E-learn: world conference on E-learning in corporate, government, healthcare, and higher education (pp 2647-2652). Association for the Advancement of Computing in Education (AACE)

9. George D, Mallery P (1999) SPSS for windows step by step: a simple guide and reference. Contemp Psychol 44:100-100

10. Ghergulescu I, Muntean CH (2012) Measurement and analysis of learner's motivation in game-based elearning. In assessment in game-based learning (pp 355-378). Springer, New York

11. Ghinea G, Ademoye O (2012) User perception of media content association in olfaction-enhanced multimedia. Applications ACM Trans Multimed Comput Commun Appl 8(4):52:1-52:5219. https://doi. org $/ 10.1145 / 2379790.2379794$

12. Ghinea G, Ademoye O (2015, November) Olfactory media impact on task performance: the case of a word search game. In 2015 International Conference on Interactive Mobile Communication Technologies and Learning (IMCL) (pp 296-300). IEEE

13. Ghinea G, Chen SY (2006) Perceived quality of multimedia educational content: a cognitive style approach. Multimedia Systems 11(3):271-279

14. Ghinea G, Chen SY (2008) Measuring quality of perception in distributed multimedia: verbalizers vs. imagers. Comput Hum Behav 24(4):1317-1329

15. Ghinea G, Andres F, Gulliver S (eds) (2011) Multiple sensorial media advances and applications: new developments in MulSeMedia. IGI Global, pp 344

16. Ghinea G, Timmerer C, Lin W, Gulliver SR (2014) Mulsemedia: state of the art, perspectives, and challenges. ACM Trans Multimed Comput Commun Appl (TOMM) 11(1s):17

17. Goldstein EB (2010) Sensation and perception. 8th International Edition. Belmont, CA (US): Wadsworth

18. Gonçalves F, Cabral D, Campos P, Schöning J (2017, September) I smell creativity: exploring the effects of olfactory and auditory cues to support creative writing tasks. In IFIP Conference on Human-Computer Interaction (pp 165-183). Springer, Cham 
19. Kaye JN (2001) Symbolic olfactory display. Doctoral dissertation, Massachusetts Institute of Technology

20. Kim JD, Choi JH, Lim SJ, Park SD, Kim JJ, Ahn CH (2015) Development of scent display and its authoring tool. ETRI J 37(1):88-96

21. Kwok RCW, Cheng SH, Ip HHS, Kong JSL (2009, October) Design of affectively evocative smart ambient media for learning. In Proceedings of the 2009 workshop on Ambient media computing (pp 65-76). ACM

22. Leenders M, Smidts A, Haji A (2019) Ambient scent as a mood inducer in supermarkets: the role of scent intensity and time-pressure of shoppers. J Retail Consum Serv 48:270-280. https://doi.org/10.1016/j. jretconser.2016.05.007

23. Mayer RE (2002) Cognitive theory and the design of multimedia instruction: an example of the two-way street between cognition and instruction. New Dir Teach Learn 2002(89):55-71

24. Mehta MA (2010) Spatial memory in humans. In: Stolerman IP, Price LH (eds) Encyclopedia of psychopharmacology. Springer, Berlin Heidelberg, pp 1262-1266

25. Miyaura M, Narumi T, Nishimura K, Tanikawa T, Hirose M (2011, March) Olfactory feedback system to improve the concentration level based on biological information. In 2011 IEEE Virtual Reality Conference (pp 139-142). IEEE

26. Murray N, Qiao Y, Lee B, Karunakar AK, Muntean GM (2013, February) Subjective evaluation of olfactory and visual media synchronization. In Proceedings of the 4th ACM Multimedia Systems Conference (pp 162-171). ACM

27. Murray N, Lee B, Qiao Y, Miro-Muntean G (2016) The impact of scent type on olfaction-enhanced multimedia quality of experience. IEEE Trans Syst Man Cybern Syst 47(9):2503-2515

28. Murray N, Ademoye OA, Ghinea G, Muntean GM (2017) A tutorial for olfaction-based multisensorial media application design and evaluation. ACM Comput Surv 50(5):67

29. Noguchi D, Sugimoto S, Bannai Y, Okada KI (2011, May) Time characteristics of olfaction in a single breath. In Proceedings of the SIGCHI Conference on Human Factors in Computing Systems (pp 83-92). $\mathrm{ACM}$

30. Pellas N, Fotaris P, Kazanidis I, Wells D (2018) Augmenting the learning experience in primary and secondary school education: a systematic review of recent trends in augmented reality game-based learning. Virtual Reality 23:329-346. https://doi.org/10.1007/s10055-018-0347-2

31. Ranasinghe N, Nguyen TNT, Liangkun Y, Lin LY, Tolley D, Do EYL (2017, October) Vocktail: a virtual cocktail for pairing digital taste, smell, and color sensations. In Proceedings of the 25th ACM international conference on Multimedia (pp 1139-1147). ACM

32. Richard E, Tijou A, Richard P, Ferrier JL (2006) Multi-modal virtual environments for education with haptic and olfactory feedback. Virtual Reality 10(3-4):207-225

33. Saleme E, Covaci A, Mesfin G, Santos C, Ghinea G (2019) Mulsemedia DIY: a survey of devices and a tutorial for building your own Mulsemedia environment. ACM Comput Surv 52(3):1-29

34. Sauro J (2011a) Measuring usability with the system usability scale (sus). Retrieved 10 January 2019, from https://measuringu.com/sus/

35. Sauro J (2011b) A practical guide to the system usability scale: background, benchmarks \& best practices. Measuring Usability LLC

36. Sprinkle R (1999) The power of aroma and the olfactory experience in the classroom. Teaching English in the Two Year College 27(2):188. Retrieved from https://search.proquest.com/docview/220939390 ?accountid $=14494$

37. Stafford LD, Salehi S, Waller BM (2009) Odors cue memory for odor-associated words. Chemosens Percept 2(2):59-69

38. Sugimoto S, Noguchi D, Bannnai Y, Okada K (2010, October). Ink jet olfactory display enabling instantaneous switches of scents. In Proceedings of the 18th ACM international conference on Multimedia (pp 301-310). ACM

39. Suzuki R, Homma S, Matsuura E, Okada KI (2014, November) System for presenting and creating smell effects to video. In Proceedings of the 16th International Conference On Multimodal Interaction (pp 208215). ACM

40. Yuan Z, Chen S, Ghinea G, Muntean GM (2006, April) Using olfactive virtual environments for learning organic molecules. In International Conference on Technologies for E-Learning and Digital Entertainment (pp. 1223-1233). Springer, Berlin, Heidelberg

41. Yuan Z, Chen S, Ghinea G, Muntean GM (2014) User quality of experience of mulsemedia applications. ACM Transactions on Multimedia Computing, Communications, and Applications (TOMM), 11(1s), 15

42. Zou L, Tal I, Covaci A, Ibarrola E, Ghinea G, Muntean GM (2017, June) Can multisensorial media improve learner experience?. In Proceedings of the 8th ACM on Multimedia Systems Conference (pp 315-320). $\mathrm{ACM}$ 
Publisher's note Springer Nature remains neutral with regard to jurisdictional claims in published maps and institutional affiliations.

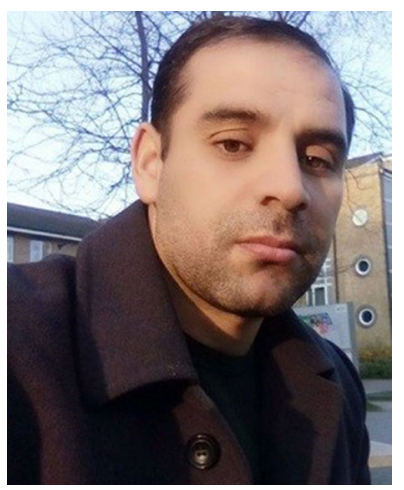

Anas Ali Alkasasbeh is a doctorate candidate in the Computer Science Department at at Brunel University London, UK. His research interests include multimedia/mulsemedia systems, e-learning, interactive multimedia, and Quality of Experience.

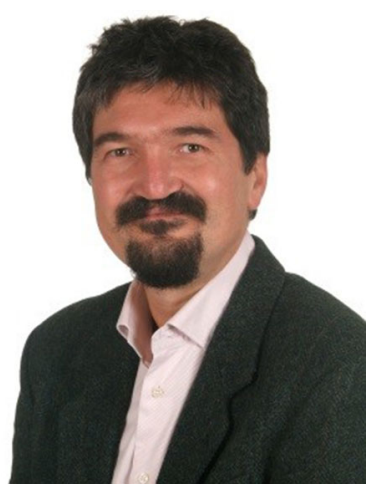

Gheorghita (George) Ghinea is Professor of Mulsemedia Computing in the Department of Computer Science at Brunel University in the United Kingdom. His research activities lie at the confluence of Computer Science, Media and Psychology. In particular, his work focuses on the area of perceptual multimedia quality and the endto-end communication systems incorporating user perceptual requirements. His area of expertise involves eyetracking, telemedicine, multi-modal interaction, ubiquitous and mobile computing. He has authored over 300 publications and co-edited two books on Digital Multimedia Perception and Design, and Multiple Sensorial Media Advance and Applications. He consults regularly for both public and private institutions within his research area and is currently the lead Brunel investigator of NEWTON - Networked Labs for Training in Sciences and Technologies for Information and Communication, an H2020 project. 